\title{
An Experimental Characterization for Injection Quantity of a High-pressure Injector in GDI Engines
}

\author{
Wen-Chang Tsai * ${ }^{*}$ and Tung-Sheng Zhan \\ Department of Electrical Engineering, Kao Yuan University, Kaohsiung 82151, Taiwan; t21016@cc.kyu.edu.tw \\ * Correspondence: t20045@cc.kyu.edu.tw; Tel.: +886-7-6077018
}

Received: 28 August 2018; Accepted: 27 September 2018; Published: 3 October 2018

check for updates

\begin{abstract}
The high-pressure (HP) injector is a highly dynamic component requiring careful voltage and pressure input modulation to achieve the required fuel injection quantities of gasoline direct injection (GDI) engines. Accurate fuel injection curves are a key influence for this technology, and therefore, will require an accurate estimation of fuel flow rate to be realized. In order to be driven to rapid response with respect to solenoid valve coils, HP injectors typically require to be designed to be capable of rapid response in GDI engines. In this paper, the design and analysis of the proposed injector drive circuit are presented. Next, the effects of total pulse width, injector supply voltage, fuel system pressure, and pulse width modulation (PWM) operation on fuel injection quantities of an HP injector are measured for achieving robust performance and stability in the presence of bounded errors of the GDI injectors due to total pulse width, injector's supply voltage, fuel pressure and PWM operation. Additionally, the fuel injection quantities of the HP injector are measured by tuning the parameters of the injector drive circuit with the PWM operation. These are defined as the fuel injection curves. Finally, experimental results are provided for verification of the proposed injector drive circuit.
\end{abstract}

Keywords: high-pressure injector; GDI engine; fuel injection quantities; injector drive circuit

\section{Introduction}

Many advanced solenoid fuel injection techniques have been developed to be implemented in various investigations of gasoline direct injection (GDI) engines [1]. The effects of fuel injection pressure have been studied as a variation on PM emissions from a SGDI engine. It was found that the particle number emissions decreased at higher injection pressure. Accurate injection control with rapid response will have some benefit of reducing fuel injector deposits and reducing particulate emissions from GDI engines [2,3]. Particulate number (PN) emissions from GDI engines and their control techniques have been reviewed [4,5]. The electronic unit injector is the major component in the high-pressure fuel injection system. The injector drive circuit has been optimized and projected to generate optimal values of two-stage currents by a coupled simulation of injector electromagnetic, needle rigid body motion and a computational fluid dynamics model [6,7]. Two-stage current shapes were conducted into the analysis of the performance of the drive circuits and were found to be the optimal power strategy for driving the fuel injector under different supply pressures [8]. The design of experiments (DOE) optimized the injector drive circuit by using the Taguchi method. The experiments of the HP injector driving circuit were conducted for the fuel injection quantity of the HP injector by controlling the fuel pressure and voltage across the solenoid coil, which further increased the response speed of the valve. Experimental results showed that the current drive circuit is feasible and reliable to implement for injection quantity of the HP injector [9]. The injector drive circuit was designed in a three-stage driving current with adjustable pulse width modulation (PWM) duties added to last pulse operation, and simulated by using PSpice software. The electrical drive circuit for the 
high-pressure GDI injector was developed for a 500 c.c. motorbike engine [10]. The different types of power losses associated with a solenoid injector were investigated. Remarkable differences in the power losses and the performances of the injector were found while it worked within different driven strategies. Simulation results of power losses were investigated and compared to experimental results to verify its feasibility [11]. The experimental data of the HP fuel injection system was investigated by various electrical drive circuit designs proposed for the HP injector [12-15].

Controllers for GDI injectors have been established; however, further research is required to apply and conduct for the custom-made GDI injectors in the GDI engines. The methodology and fuel injection curves can give some useful directions for designers and other researchers who will do the investigations on analyzing and tuning the GDI control systems for performance and robustness. The proposed experimental investigation on the characterization of a high-pressure GDI injector, which is the main contribution of the paper, is interesting and helps researchers to achieve robust performance and stability in the presence of bounded errors of the GDI injectors due to total pulse width, first-stage turn-on pulse width, injector's supply voltage, fuel pressure, and PWM operation. Therefore, depending on the application and required robust controller, the experimental investigation on the characterization of a high-pressure GDI injector is important. In this study, injector drive circuits were designed to satisfy the rapid response and sustain the instantaneous surge currents for various HP GDI injectors. The designed electric drive circuit was tested to verify its feasibility. The experiment for the GDI injection quantities was conducted under 60-100 bars of fuel pressure, $1200-2000 \mu$ s injecting pulse duration, and DC 40-70 V executing supply voltage. Additionally, PWM on/off control operation was introduced to the holding current during the last pulse duration for rapid response time to turn off the GDI injector. Design and analysis of the proposed injector drive circuit are presented in the paper. Next, effects of total pulse width, injector supply voltage, fuel system pressure, and PWM operation on fuel injection quantities of an $\mathrm{HP}$ injector were measured. The measured data of the HP injector fed by the injector drive circuit are defined in fuel injection curves. Results show that the HP fuel supply system for GDI engines is capable of operating stably and assuring the accurate injection quantities by the three-pulse power metal oxide semiconductor field effect transistors (MOSFETs) electric drive circuit.

\section{The Modified KYMCO Xciting-500 GDI Engine}

The pressure at which the fuel is injected into the combustion chamber through an injector is an important factor, as it directly affects the performance of an engine. GDI engines are injected into the combustion chamber at pressures ranging from 100 bars to 120 bars (e.g., in 1.6 L Gamma GDI and ThetaNu 2.0 L GDI). Modern GDI injectors can even have injection pressures up to 200 bars (e.g., in 1.6 Ford Ecoboost GTDi and LambdaII 3.0 V6 GDI). However, the fuel pressure system for the present study, carried out on the modified KYMCO Xciting-500 GDI engine, is at 100 bars. Figure 1a illustrates the cylinder head of the port fuel injection (PFI) engine. The specifications of the base engine with the PFI are shown in Table 1. Figure $1 \mathrm{~b}$ shows a schematic picture of this PFI engine, with certain modifications in its cylinder head. Limited by the structure of the cylinder head, the fuel injector and the spark plug are, respectively, center-mounted at an induced angle of the left-hand $10^{\circ}$ and the right-hand $12^{\circ}$ to the vertical plane between the intake and exhaust valves. A testing study was carried out on the modified KYMCO Xciting-500 GDI engine. An experimental configuration of a 500 c.c. GDI engine system is shown in Figure 2. 


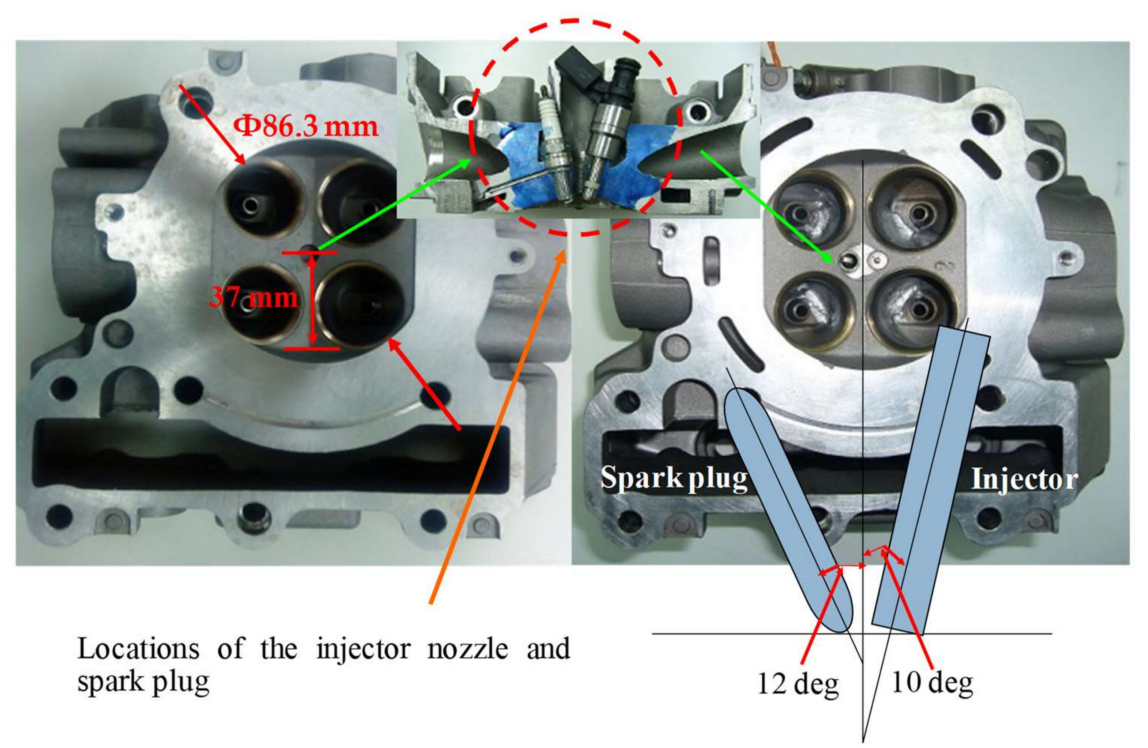

(a) Cylinder head of the port fuel injection (b) Cylinder head of the gasoline direct (PFI) engine.

injection (GDI) engine after modification.

Figure 1. Cylinder head of a KYMCO Xciting-500 engine before and after modification.

Table 1. Basic engine specification.

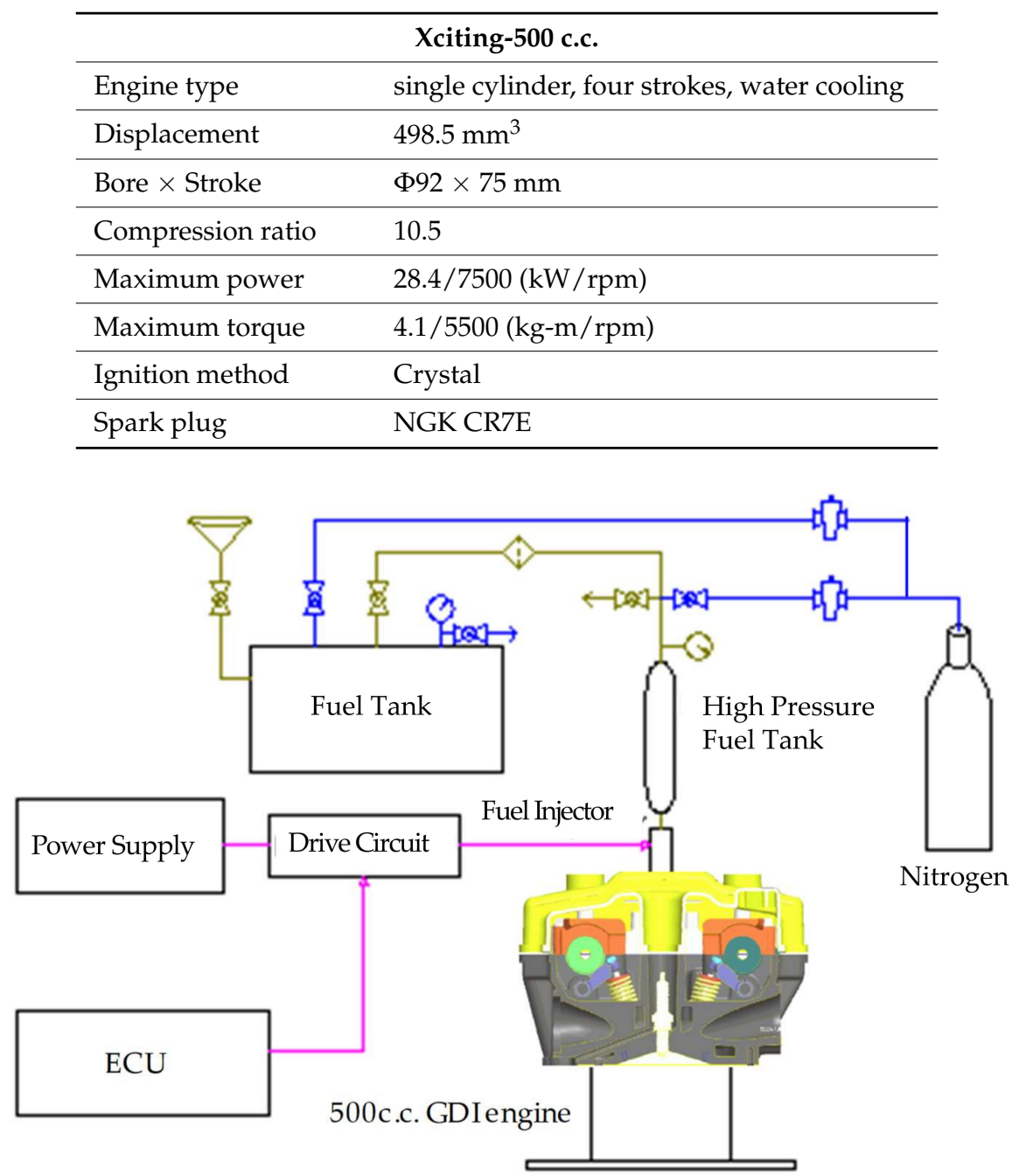

Figure 2. Experimental test configuration of a 500 c.c. GDI motorbike engine system. 


\subsection{The High-Pressure GDI Fuel Injection System}

Gasoline Direct Injection technology is a superior option due to its advantages of fuel economy and emission reduction from gasoline-powered vehicles. An HP fuel supply system in GDI engines directly injects fuel to the cylinder of the engine. The HP fuel injector is a key component of a GDI fuel injection system. The injection timing and duration is electronically controlled by an Electronic Control Unit (ECU). Various pulse durations can be sent to the fuel injector according to the engine's actual operating conditions from the signals of engine sensors. The HP fuel injection system consists mainly of an HP fuel injector, electrical drive circuit, the fuel supply system, and an ECU. The constant pressure resource arranging from 60 to 100 bars provides for the injector of the fuel supply system. The ECU computes and analyzes the analogue and digital input signals from various engine sensors, controlling the injection pulse duration and timing of the injector. The engine performances can be improved by more rapid engine response in throttle positions, and more precise control of air/fuel ratio. In this study, a Bosch GDI single-hole injector was installed and tested on the cylinder head of a 500 c.c. motorcycle engine.

\subsection{Fuel Supply System}

The fuel supply system is similar to the conventional design of GDI engines in HP fuel containers. This research used a Bosch GDI single-hole injector that was installed in the test device. Its pressure could be operated between 60 and 100 bars (max) which has been commonly used in some GDI engines. In the fuel supply system illustrated in Figure 2, the HP nitrogen bottle pulls the operating pressure of the stainless fuel cylinder up to 60-100 bars (max). It was expected to maintain this constant value to avoid any disturbances to the GDI injector performance caused by the gasoline pump pressure dip at high speed operation of motorcycle engines. The cylinder pressure was maintained at a constant value through regulating HP nitrogen flow. The pressure fluctuation of the fuel container, caused by closing and opening of the nozzle, was about 0.5 bars.

The experimental equipment for characterizing the dynamic performances of the HP GDI injector is illustrated in Figure 3a. According to the test requirements, the parameters of the fuel injection system were calibrated properly to each part of the injector drive circuit. After the characterization of the injector's dynamic performances, the fuel pressure in the GDI Bosch injector was mounted onto a 500 c.c. motorcycle engine cylinder head was set at 60-100 bars for the running test.

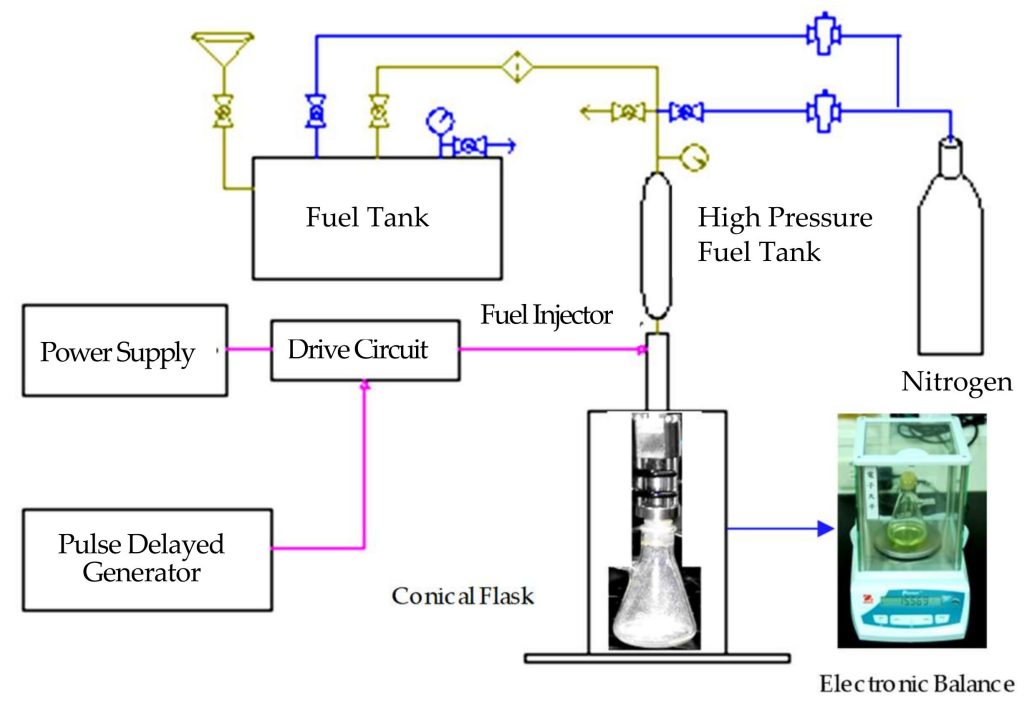

(a) Injection quantity measurements of the high-pressure (HP) GDI injector.

Figure 3. Cont. 


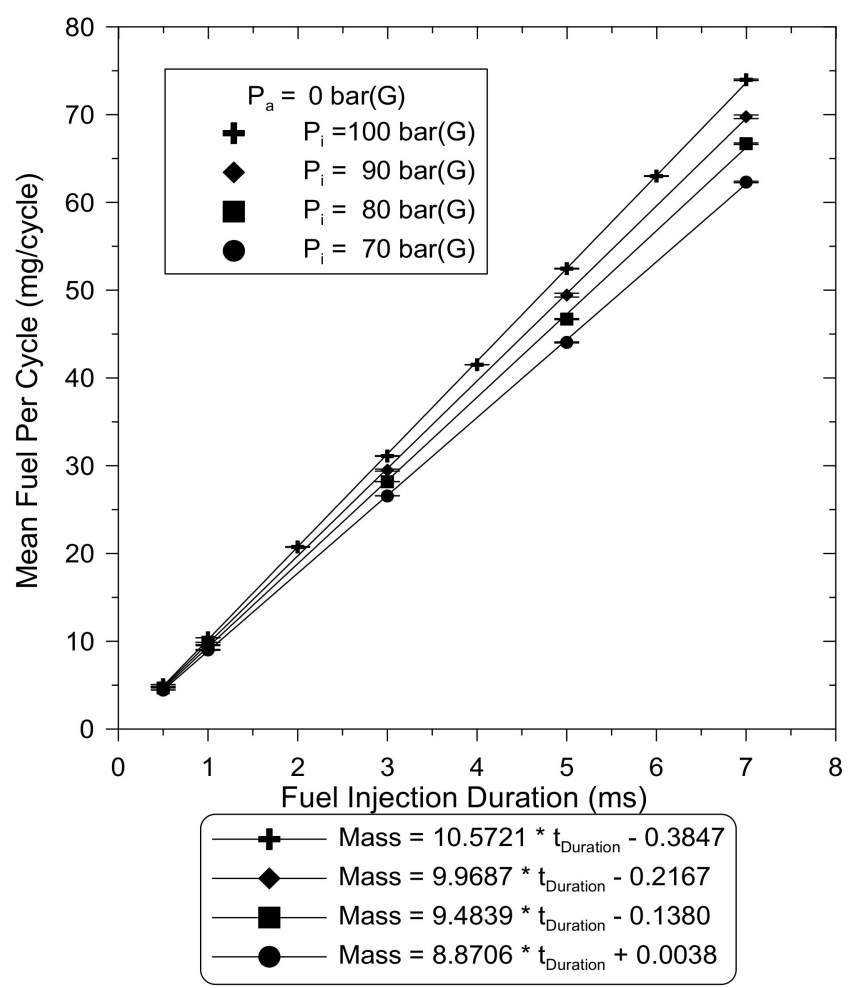

(b) Effect of various fuel pressures and pulse widths on fuel injection quantities of the GDI injector fed by the single-pulse (12 A) driving current.

Figure 3. Investigations on fuel injection quantities of the GDI injector.

\subsection{High-pressure Fuel Injector}

In order to investigate the effect of the total pulse width on the fuel injection quantities, the power voltage was supplied by DC $60 \mathrm{~V}$ and the pressure of the fuel supply system were set to and 100 bars. An HP GDI injector is preferred for engines with small displacement in relation to the optimum angle of fuel atomization and spray penetration. However, due to the constraints of limited research into the development of small motorcycle GDI engines and the required time to design, test, modify and calibrate such a swirl injector, the Bosch GDI single-hole injector was used, based on analyzing the working principle of the electronic controlled injector. The injector was driven by a three-stage current waveform in accordance with the injector characteristics. It uses the solenoid valve as an electricity-fluid conversion element and controls the injection parameters precisely through the reference current waveforms. The minimum injection quantities are approximately $1200 \mu \mathrm{s}$ of pulse duration with $14.07 \mathrm{mg}$ in each pulse. This satisfies the requirements of the idle operation of motorcycle engines. Effects of various fuel pressures and pulse widths on fuel injection quantities for the GDI injector fed by the single-pulse (12 A) driving current was examined and characterized as illustrated in Figure 3b.

\subsection{Mathematical Model}

The injector uses a magnetic force to transmit energy from the solenoid actuator to the needle. A TTL signal by a pulse delayed generator is sent to the three-stage injector drive circuit as the input to the system. This triggers the driver to charge the solenoid coil up to DC $70 \mathrm{~V}$. As current flows to the actuator, the 12 A current produced is sufficient to rapidly draw back the nozzle needle of the GDI injector when the fuel injecting pressure is set at 100 bars. The second drive pulse drives the GDI injector to produce the $5 \mathrm{~A}$ holding current and keep continuous injection. The last drive pulse of the drive circuit supplies the $3 \mathrm{~A}$ current to hold the nozzle needle for the GDI injector. Meanwhile, the injection status of the GDI injector continues, though it is ready to stop squirting. The schematic 
diagram of a high-pressure solenoid injector is shown in Figure 4a. The electromechanical model of the electronically controlled injector is comprised of two types: hydraulic volumes and moving apartments, according to each part's hydraulic and dynamical characteristics. Fuel in hydraulic volumes can be compressed and its characteristics are based on the following equations [8]:

$$
\Delta P=\frac{\Delta V}{V}
$$

Fuel flow in and out of each volume can be described as Bernoulli equations:

$$
\mathrm{Q}=\mu A \sqrt{\frac{2 \Delta P}{\rho}}
$$

According to the compression equation and the Bernoulli equation, we can get a function to describe the pressure change in hydraulic volume:

$$
\frac{d P}{d t}=\left[\sum Q_{\text {in }}+Q_{\text {leakin }}-Q_{\text {out }}-Q_{\text {leakout }}+\sum A \frac{d x}{d t}\right] \cdot \frac{E}{V}
$$

where $Q_{i n}, Q_{o u t}$ are the flow rate of fuel flowing in and out volume; $Q_{\text {leakin }}, Q_{\text {leakout }}$ are the flow rate of fuel leaking in and out volume; $A$ is the cross section of moving parts(needle); and $\mathrm{x}$ is the displacement of moving parts (needles). The dynamics of the moving components of the injector (needle and control piston) is calculated with the following, one-dimensional momentum equation [8]:

$$
\mathrm{m} \frac{d^{2} x}{d t^{2}}+\zeta \frac{d x}{d t}+\mathrm{kx}=\sum F_{m}+\sum F_{h}+\sum F_{e}
$$

where $x$ is the displacement of moving component; $F_{m}$ the mechanical force; $F_{h}$ the hydraulic force; and $F_{e}$ the electromagnetic force. The electromagnetic actuator is one of the most important parts of the injector. The actuator can be sorted into electronic subsystem, magnetic subsystem, mechanical subsystem, and hydraulic subsystem. The simulation model is shown in Figure $4 \mathrm{~b}$. The relationships among each subsystem were formulated in the following equations:

$$
\left\{\begin{array}{l}
\left(L_{s}+L_{a}\right) \frac{d i}{d t}+\left(R_{s}+R_{a}+R_{L}\right) i+V c=V o \\
i=C \frac{d V c}{d t} \\
\frac{d^{2} x}{d t^{2}}=\frac{1}{m} F_{m a g}-\frac{1}{m} k\left(x+x_{0}\right)-\frac{1}{m} F_{h}-\frac{1}{m} \zeta \frac{d x}{d t} \\
F_{m a g}=\frac{\mu_{0}(N i)^{2} S_{a}}{2(\delta-x)^{2}} \\
F_{h}=f\left(x, \frac{d x}{d t}, P_{c o n}, P_{b p a}\right)
\end{array}\right.
$$

where $L_{\mathrm{S}} / L_{a}$ are the input inductance and the actuator inductance, $i$ is the actuator current; $R_{\mathrm{S}} / R_{a}$ are the input inductance and the actuator resistance; $R_{L}$ are the resistance to limit the peak current flow; $\mathrm{V}_{\mathrm{o}}$ is the initial injector actuator voltage across the actuator, $V_{c}$ and $C_{p}$-capacitor charge voltage and capacitance; $x, m, \zeta$ are the armature displacement, moving mass and damping constant; $F_{m a g}$ is the magnetic force; $\mu_{0}$ is the magnetic permeability in vacuum; $N$ is the coil number; $S_{a}$ is the magnetic flux cross section area; $\delta$ is the initial gap; $F_{h}$ is the hydraulic force; $P_{c o n}$ is the control volume pressure; and $P_{b p a}$ is the back pressure of actuator. 


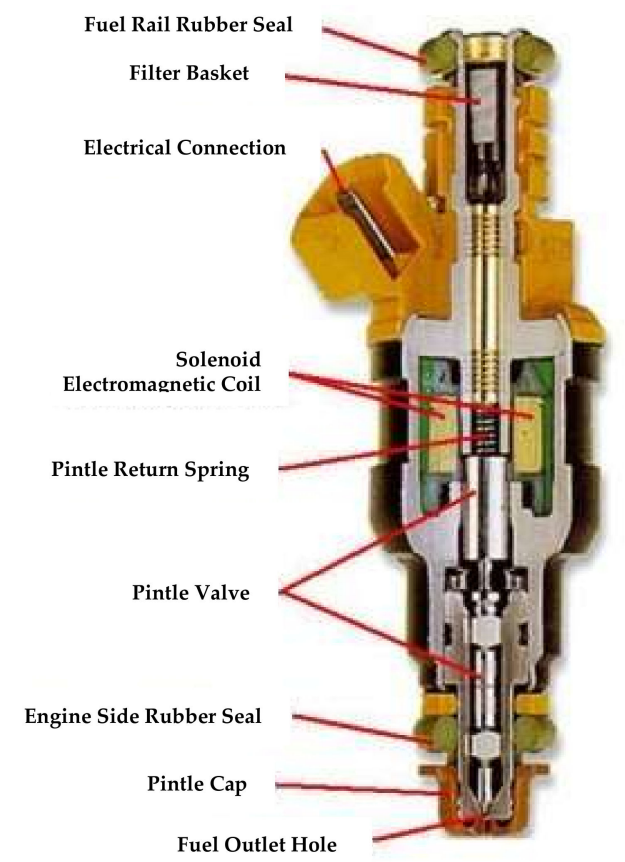

(a) Schematic diagram of a Bosch EV1 high-pressure fuel injector.[16]

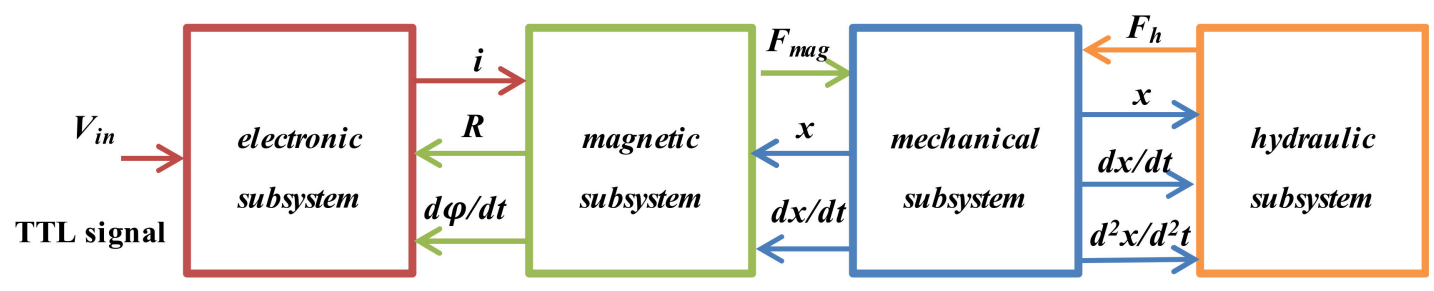

(b) Schematic diagram for a high-pressure GDI injector.

Figure 4. The high-pressure GDI injector Control System.

\subsection{Data Acquisition Card and ECU Controller}

The Electronic Control Unit (ECU) was designed to be capable of precise A/F ratio control according to the requirements of various engine operating conditions. The injection pulse width and throttle angle can be tuned by the ECU to ensure proper A/F ratio and stable power output requirements (as depicted in Figure 5). The ECU includes the dsPIC30F4011 controller, signal acquisition card, and the printed circuit board (PCB), generating the three-stage injection pulses as well as the PWM control signal. The signals such as engine speed, top dead center (TDC), throttle position, fuel flow volume, air flow, water temperature, fuel supply pressure, etc., were received from various engine sensors. These signals were processed and then transmitted to the microchip dsPIC30F4011 for monitoring the operating conditions of motorcycle engines. The controller performed a logic operation for the $A, Z$, and proximity switch signals of motorcycle engines to determine the TDC on intake and compression of engines. The TDC on compression of engines is a reference (based) point. By using the reference point, the dsPIC30F4011 performed an arithmetic computation of engine parameters as speed, torque, throttle position, air flow, and fuel supply pressure to achieve the delay timing and duration of the injection driving pulse. The PWM control was added to the last pulse duration of injector driving current to rapidly turn off the GDI injector. The pulse and PWM control circuit output the two different duration injection pulses and a PWM control signal to drive the power MOSFETs in the injector driving circuit. Therefore, three-stage (12/5/3 A) peak and holding current profiles were supplied to the solenoid valve coils of the injector to induce the electromagnetic force to draw back and hold the nozzle needle of a GDI injector. The control system configuration for the 500 c.c. motorcycle engine is illustrated in Figure 5. 


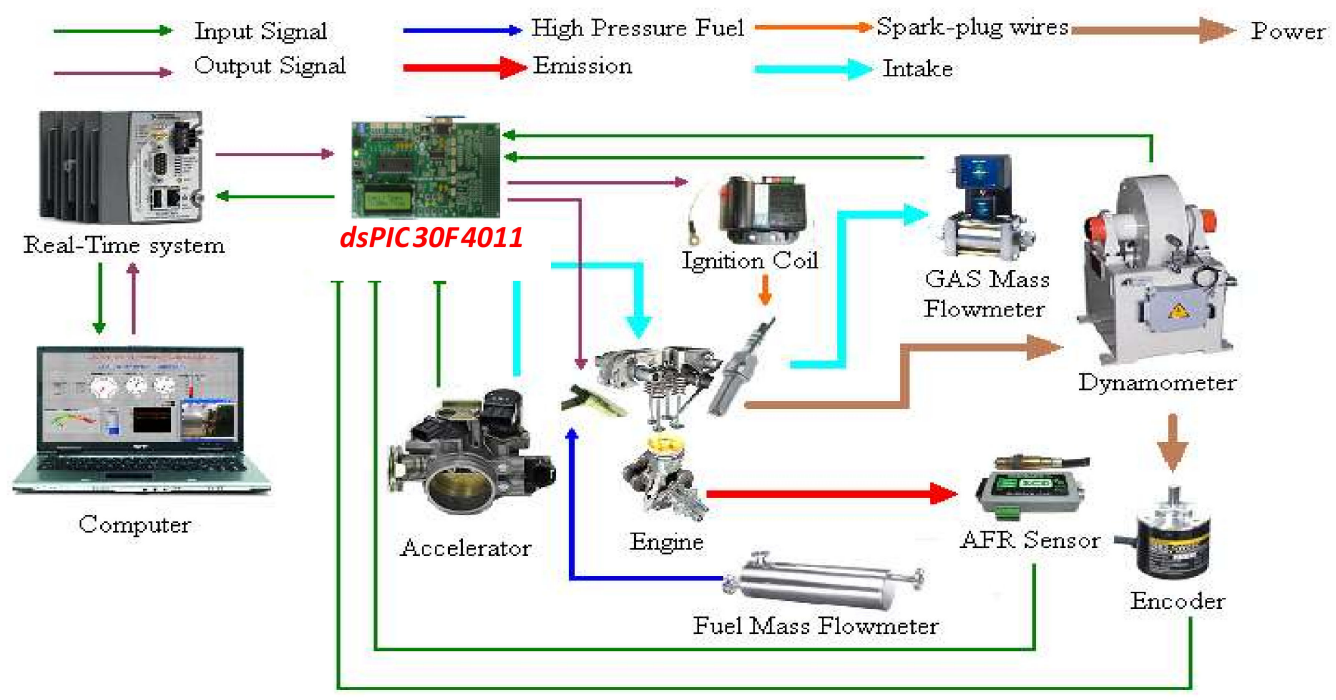

Figure 5. The Control System Diagram for a 500 c.c. motorcycle Engine.

\section{Development of Fuel Injector Drive Circuit}

This research developed various drive circuits for the HP fuel supply system of a 500c.c. GDI motorcycle engine. The initial design of the drive circuit for the HP GDI fuel supply system was developed by three-stage power transistors. The designed drive circuit was tested with a high-frequency drive pulse to execute the experiments of high-speed fuel injection quantities. The anti-noise photo coupler 4N35 drive ICs, driven by the first and second pulses, were usually damaged due to surge voltages and currents exceeding their operating rating. To improve the above faulty design or simplify the drive circuit, three-stage power MOSFETs drive circuits were developed. The GDI injector drive circuits were developed to be a practical printed circuit board (PCB) to test the effect of engine speeds, pressures of the GDI fuel supply system, driver supply voltages, first stage turn-on driving currents, pulse durations, and PWM control added to the last pulse duration on the dynamic performance of the GDI injector. Therefore, the power MOSFETs components were adopted to design the GDI injector drive circuit under the operations of high-frequency surge voltages and currents. The procedures for the simulation and practical designs are illustrated as below.

\subsection{Injector Drive Circuit}

The governing equation is then obtained for the simple resistor-inductor circuit (RL Circuit) using KVL as follows:

$$
V_{S C}=I_{S C} R_{S C}+L_{S C} \frac{d I_{S C}}{d t}
$$

where $V_{S C}$ is the voltage across fuel injector solenoid coils; $R_{S}$ is the resistance of fuel injector solenoid coils; and $L_{S C}$ is the inductance of fuel injector solenoid coils.

From the above Equation (7), the coil current is expressed by:

$$
I_{S C}(t)=\frac{V_{S C}}{R_{S C}}\left(1-e^{-\frac{R_{S C} t}{L_{S C}}}\right)=\frac{V_{S C}}{R_{S C}}\left(1-e^{-\frac{t}{\tau}}\right)
$$

where $\tau$ is the electrical subsystem time constant.

The following expression for inductance of the fuel injector solenoid coil is given by [7]:

$$
L_{S C}=\frac{N^{2} \mu_{1} \frac{\pi}{4} d^{2} h}{\frac{d w}{2}+\Delta_{x} h}
$$


where $\mu 1$ is the permeability in the air $[\mathrm{H} / \mathrm{m}] ; N$ is the number of solenoid coil turns; $h$ is the pintle height [mm]; $d$ is the pintle disk diameter [mm]; $\Delta_{x}$ is the air gap [mm]; and $w$ is the non-magnetic strip width in millimeters.

In order to carry out the experiments under the operation of high-frequency surge voltages and currents, three-stage power MOSFETs were introduced in the design of the injector drive circuit. The electric drive circuit was designed and simulated for the requirements of the GDI injector characteristics in the Pspice simulation software. The Pspice model of the three-stage power MOSFETs electric drive circuit is illustrated in the Figure 6a. After simulation and experimental test, the improved electric drive circuit and PWM control were added into the last pulse duration, which was required to make a practical PCB. The PCB layouts of three-stage drive pulse and PWM control signal circuit as well as power MOSFETS drive circuit are presented in Figure $6 b, c$, respectively.

By taking the procedures of exposure, photography development, and metallurgy etching, two circuit boards were developed, after which the parts were soldered onto the PCB board. A programmable drive module based on the working principle of the injector electric drive circuit was designed, which is shown in Figure 6d,e.

Three drive pulse signals were supplied to drive the power MOSFETs switches of the electrical drive circuit via the photo coupler drive IC 4N35. The functions of the photo coupler drive IC 4N35 were anti-noise for signal processing. The DC $5 \mathrm{~V}$ trigger signals from ECU output were required to raise up to at least $15 \mathrm{~V}$ voltage level using IC $4 \mathrm{~N} 35$ photo coupler circuit to be able to drive the power MOSFETs switches M1-M3 as depicted in Figure 6a. Total turn-on injection pulse duration of the GDI injector was set at a range between $1200 \mu$ s and $2000 \mu$ s, in which the first, second, and third pulse duration were $200 \mu \mathrm{s}, 600 \mu \mathrm{s}$, and 400-1200 $\mu \mathrm{s}$, respectively. The PWM frequency (30-200 kHz) has been experimentally applied in the last pulse. It was considered to be the best compromise between reducing current ripple and limited switching action from the components: this ensured a good injector squirting response.

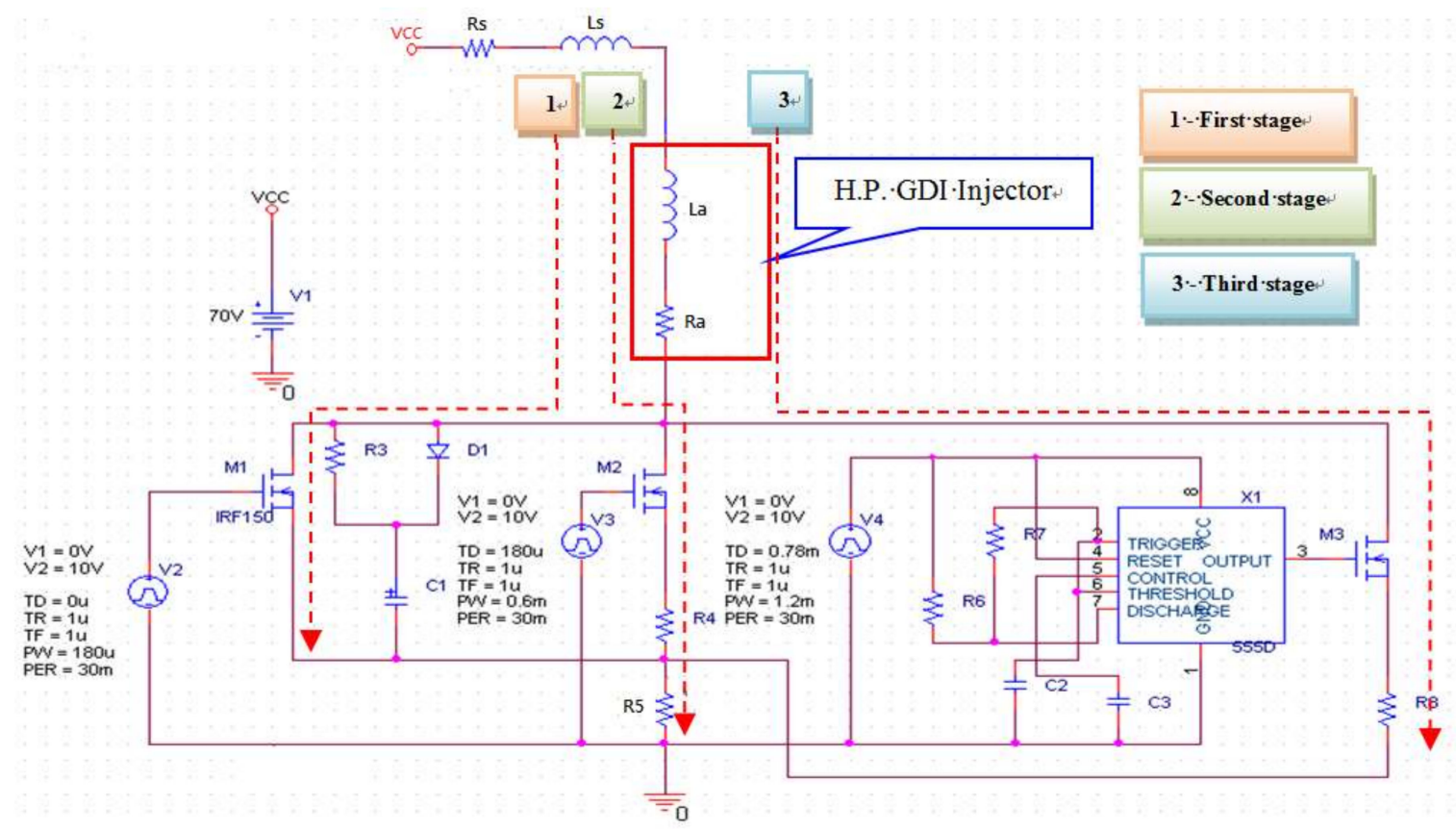

(a) Three-stage power metal oxide semiconductor field effect transistors (MOSFETS) drive circuit for the HP GDI Injector with pulse width modulation (PWM) control added to the last pulse duration.

Figure 6. Cont. 


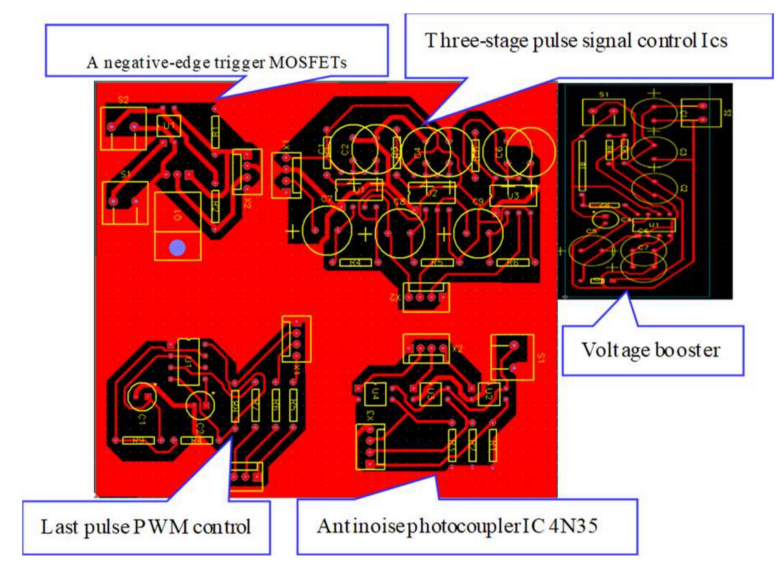

(b) The printed circuit board (PCB) layout of the three-stage driving pulse and the PWM control signal added to the last pulse operation.

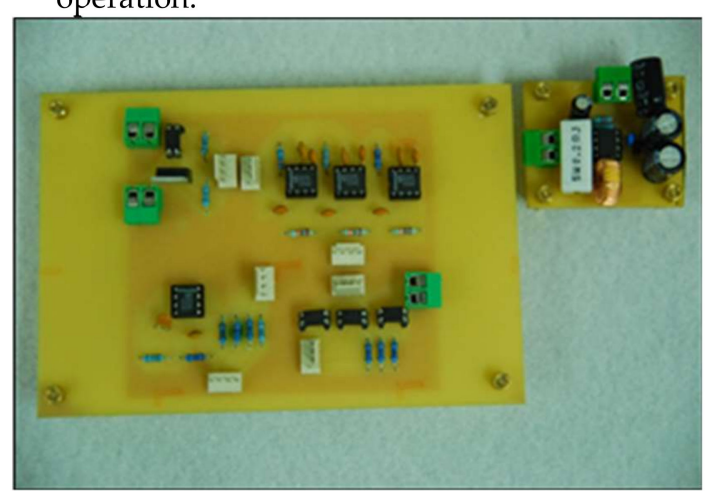

(d) Practical three-pulse signal circuit board with PWM control added to the last pulse operation.

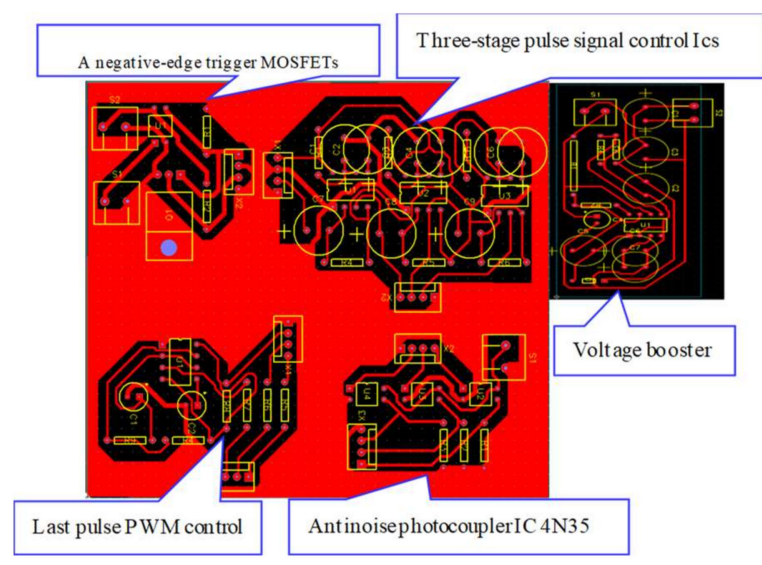

(c) The PCB layout of three-stage power MOSFETS drive circuit.

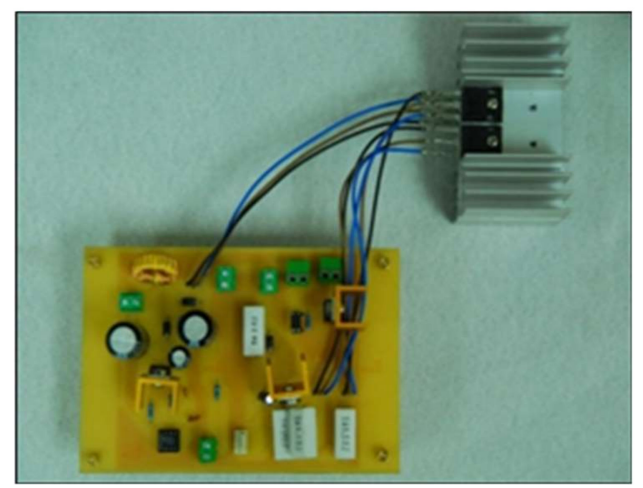

(e) The developed HP injector driving circuit board.

Figure 6. Development of the H.P. injector driving circuit.

\subsection{Experimental Procedures and Measurement Conditions}

Fuel injection quantities of the GDI injector can be controlled by adjusting the drive pulse duration. In order to understand the dynamic performance of a GDI injector, the interrelationships between the parameters of the fuel injecting system and its fuel injection quantities must be investigated. These includes total drive pulse duration, first stage turn-on peak current, the injector driver supply voltage, the operating modes added to third pulse operation to cut off the injector, and the pressure of the fuel supply system. The executing driver supply voltages, output drive pulses, and currents for the HP GDI injector were measured and displayed on the digital storage oscilloscope to meet the operating requirements of the GDI injector.

An injecting pulse signal from an ECU was fed into the three-stage power MOSFETs PCB to generate the three-stage (12/5/3 A) driving current waveforms. The GDI injector should be supplied by the three-stage 12/5/3A driving currents for $3 \mathrm{~A}$ holding current added to the last pulse duration. The holding voltage at Holding stage I (5 A) was still at a high level, though much lower than the peak voltage. At this stage, the holding voltage I is used to maintain the coil and core in firm contact. At Holding stage II ( $3 \mathrm{~A})$, when the coil and core attraction remained stable, the voltage was kept at a further reduction as based on holding stage I, to prepare for the ball valve closing. The driving method used in the three-stage current profile had the following two advantages: (1) at the holding stage, the ball valve remains open with a low current supply from the drive circuit, thus, the energy stored in the electromagnetic coil was lower, which was of benefit to decrease the closing delay time; (2) a lower hold current can protect the solenoid valve coil. At the same time, less energy can avoid the hazard of 
high temperature caused by a large current, and hence, effectively improve the dynamic response of the GDI injector. The GDI injector current profile without and with adding PWM control to last pulse duration including three-stage drive pulse signals are presented in Figure $7 \mathrm{a}, \mathrm{b}$. The orange waveform represents the first turn-on pulse signal $(I p 1=200 \mu \mathrm{s})$. The 12 A current produced was sufficient to rapidly draw back the nozzle needle of the GDI injector when the fuel injecting pressure was set at 100 bars. The second drive pulse as shown in the green waveform drove the GDI injector to produce the $5 \mathrm{~A}$ holding current and keep continuous injection. For the last drive pulse, the blue waveform, the drive circuit supplied the 3 A current to hold the nozzle needle of the GDI injector. Meanwhile, the injection status of the GDI injector continued, though it is ready to stop squirting. The three-stage currents were supplied to drive the actuators in the GDI injector for carrying out the fuel injection experiments. In the experiments, the driver supply voltage varied between $40 \mathrm{~V}$ and $70 \mathrm{~V}$. The pressure of the fuel supply system was set at a range between 60 bars and 100 bars. A power MOSFETs-switch GDI driver was designed with a wide range of injection pulse durations (1200-2000 $\mu$ s). The fuel injection quantities for four corresponding engine speed settings, $1200 \mathrm{rpm}, 2400 \mathrm{rpm}, 6000 \mathrm{rpm}$, and $9000 \mathrm{rpm}$ were measured. After completing 1000 fuel injections, the fuel injection quantities were measured in the electronic balance, and total measured fuel mass (g) was divided by 1000 to obtain the average fuel injection quantities (mg) per injection. The results characterize the dynamic performances of the GDI injector fed by the electrical drive circuit and provide the engine air-fuel ratio (AFR) control with the precise fuel injection quantities to achieve superior dynamic performances of a GDI injector.

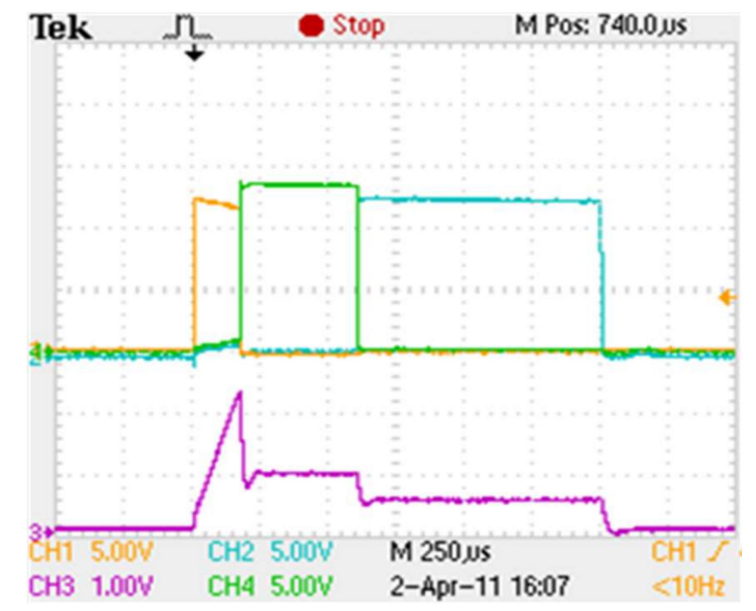

(a) The driving pulse signals and GDI injector current waveforms without PWM control added to the last pulse duration $\left(I_{p 1}=200 \mu \mathrm{s}\right)$.

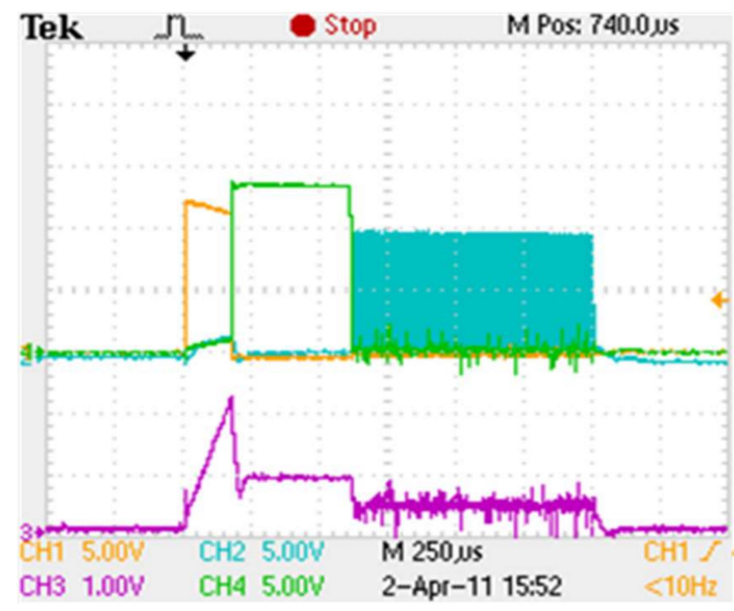

(b) The driving pulse signals and GDI injector current waveforms with PWM control added to the last pulse duration $\left(I_{p 1}=200 \mu \mathrm{s}\right)$.

Figure 7. The driving pulse signals and GDI injector current waveforms without and with PWM control added to the last pulse duration.

\section{Results and Discussions}

This type of GDI injector requires the three-stage drive circuits fed by a supply voltage to acquire three-stage driving currents. Experimental configuration is described in Table 2 and was verified based on a single-hole Bosch GDI injector. The electrical drive circuit was installed and tested in the GDI fuel injection system as illustrated in Figure 3a. The injection pulse duration was normally defined between $1200-2000 \mu$ s to evaluate the operating stability of the GDI injector application. A $5 \mathrm{~V}$ Square-pulse signal was inputted to the electrical drive circuit. The supply voltage was adjusted to range from DC $40 \mathrm{~V}$ to $70 \mathrm{~V}$ and fed the GDI injector actuator to investigate the effects of the injector supply voltage on the fuel injection quantities. Finally, experiments for two different first pulse turn-on currents (12/10 A) were conducted and compared. The experimental configuration for the spray test of the GDI injector and injection performance were observed at first pulse turn-on time $(I p 1=200 \mu \mathrm{s})$. Drive signal duration is $1500 \mu \mathrm{s}$. 
Table 2. Experimental configuration.

\begin{tabular}{cc}
\hline Condition & Description \\
\hline Supply voltages & DC 40-70 V \\
\hline Current profiles Max & $12 / 5 / 3 \mathrm{~A}$ \\
\hline Fuel pressure & $60-100$ Bars \\
\hline Fuel temperature & $30^{\circ} \mathrm{C}$ \\
\hline Number of injection samples & 1000 \\
\hline
\end{tabular}

\subsection{Effect of Total Pulse Width}

The power supply voltage and the pressure of the fuel supply system are set at DC 60V and 100 bars, respectively, to measure the fuel injection quantities by adjusting total pulse width. The injection frequency and drive pulse duration were adjusted at the above sampling speeds to measure the average fuel injection quantities. Effects of various speeds and pulse widths on fuel injection quantities of the HP injector fed by the three-stage (12/5/2.5 A) driving current are represented in the Figure 8. The following equations for characterizing the fuel injection curves are given by:

$$
\begin{gathered}
\mathrm{m}_{\text {fuel }}=-1.0984 \mathrm{t}_{\mathrm{p}}+11.567 \text { between } 1200 \text { and } 6000 \mathrm{rpm}\left(\mathrm{R}_{2}=0.9993\right) \\
\mathrm{m}_{\text {fuel }}=-0.0639 t_{p}^{2}+1.4758 \mathrm{t}_{\mathrm{p}}+11.715 \text { for exceeding } 6000 \mathrm{rpm}\left(\mathrm{R}_{2}=0.9968\right)
\end{gathered}
$$

where $\mathrm{m}_{\mathrm{fuel}}$ is the fuel injection mass $(\mathrm{g})$ and $\mathrm{t}_{\mathrm{p}}$ is the pulse duration $(\mu \mathrm{s})$

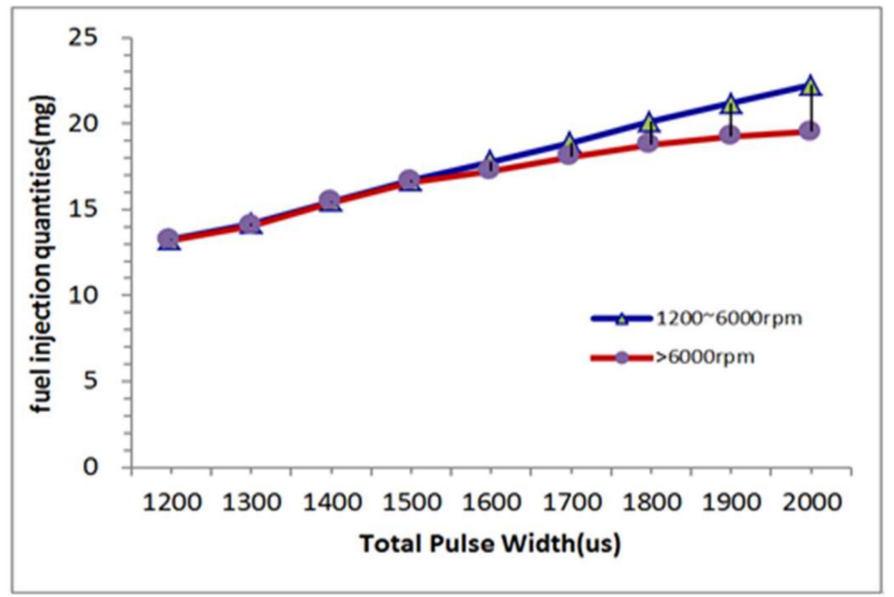

Figure 8. Effect of various speeds and pulse widths on the fuel injection quantities of the GDI injector fed by the three-pulse driving current (PWM control withdrawn from the last pulse duration).

PWM control was withdrawn from the last pulse duration. As the first drive pulse turns on the MOSFET, the actuator coils of the HP injector as charged by the DC 60V supply voltage. The first-pulse turn-on peak currents was, therefore, generated and flowed into the solenoid valve coils of the injector to induce the electromagnetic force to draw back the nozzle needle of an HP injector. Thus, the 100-bar fuel pressure forced the fuel into the experimental jar via the nozzle hole. Next, the second and third pulses triggered the second- and third-stage MOSFETs to produce the $5 \mathrm{~A}$ and 2.5 A holding currents, respectively. These two exciting currents charge the solenoid valve coils to hold the nozzle needle of the HP injector, therefore, the fuel of the HP injector would keep spurting. The HP injector was operated at an injection frequency ranging from 10 pulses/s to 75 pulses/s. The injection frequency was equal to the engine speeds from 1200 to $9000 \mathrm{rpm}$. By adjusting the fuel injection width within a range between $1200 \mu$ s and $3000 \mu$ s, the fuel injection quantities increased from 
$13.153 \mathrm{mg} /$ pulse to $22.08 \mathrm{mg} /$ pulse, of which the variation was slightly above sampling engine speeds. However, the operating frequency of the HP injector was closed to 75 pulses/s (corresponding to engine speeds at $9000 \mathrm{rpm}$ ); inadequate fuel injection quantities would begin to result in significant fuel variations exceeding $1600 \mu$ s pulse duration.

\subsection{Effect of Injector's Supply Voltage and PWM Operation}

In the practical electrical circuits of motorcycle GDI engines, the injector's supply voltage drop significantly influences the fuel injection quantities during high speed injecting operation. The effect of the injector's supply voltage and PWM control on the fuel injection quantities was required to investigate the fuel injection experiments. An injecting pulse signal from the ECU was fed into the three-stage power MOSFETs PCB to generate the three-stage (12/5/3 A) current waveforms. The three-stage currents were supplied to drive the actuators in the HP injector. In the experiments, the driver supply voltage varied from 40 to $70 \mathrm{~V}$; the pressure of the fuel supply system was set at 100 bars. A power MOSFETs-switch HP driver was designed with a wide range of injection pulse durations (1200-2000 $\mu \mathrm{s})$. The fuel injection quantities for three engine speed settings (1200 rpm, $2400 \mathrm{rpm}$, and $6000 \mathrm{rpm}$ ) were measured. The DC supply voltage was supplied to drive the actuators in the HP injector for carrying out the fuel injection experiments. The effects of the injector supply voltage on the fuel injection quantities of the HP injector fed by the three-stage 12/5/2.5 A (without PWM mode) and 12/5/3 A driving current (with PWM mode) were investigated. The pressure of the fuel supply system was set at 100 bars. An injecting pulse duration $(1500 \mu \mathrm{s})$ was sent to the three-stage power MOSFETs' HP driver to measure the fuel injection quantities for three engine speed settings at $1200 \mathrm{rpm}, 2400 \mathrm{rpm}$, and $6000 \mathrm{rpm}$. The effect of the injector supply voltages on the fuel injection quantities of the HP injector without PWM control added to the 2.5 A holding currents during the last pulse duration is presented in Figure 9a. In Figure 9a, the fuel injection quantities fed by the DC $40 \mathrm{~V}$ injector supply voltage are $15.641 \mathrm{~g}, 15.568 \mathrm{~g}$, and $15.729 \mathrm{~g}$ at $1200 \mathrm{rpm}, 2400 \mathrm{rpm}$, and $6000 \mathrm{rpm}$, respectively. They are almost the same, irrespective of engine speeds. When the injector supply voltage raised to DC $70 \mathrm{~V}$, fuel injection quantities increased to $16.935 \mathrm{~g}$ from $15.641 \mathrm{~g}$. The equations for characterizing the fuel injection curves are given by:

$$
\begin{gathered}
\mathrm{m}_{\text {fuel }}=-0.0003 V_{s}^{2}+0.0736 \mathrm{~V}_{\mathrm{s}}+13.175\left(\mathrm{R}_{2}=0.9992\right) \text { between } 1200 \text { and } 6000 \mathrm{rpm} \\
\mathrm{m}_{\text {fuel }}=-0.0013 V_{s}^{2}+0.1773 \mathrm{~V}_{\mathrm{s}}+10.722\left(\mathrm{R}_{2}=0.9994\right) \text { for exceeding } 6000 \mathrm{rpm}
\end{gathered}
$$

where $\mathrm{m}_{\text {fuel }}$ is the fuel injection mass $\left(\mathrm{mg} /\right.$ pulse) and $\mathrm{V}_{\mathrm{s}}$ is the power supply voltage $(\mathrm{V})$.

PWM control was added to the $2.5 \mathrm{~A}$ holding currents during the last pulse operation as shown in Figure 9b. These results show that the fuel injection quantities were varied with the injector supply voltage. However, the fuel injection quantities fed by the DC $40 \mathrm{~V}$ injector supply voltage showed $9.314 \mathrm{~g}, 9.328 \mathrm{~g}$, and $9.952 \mathrm{~g}$ at $1200 \mathrm{rpm}, 2400 \mathrm{rpm}$, and $6000 \mathrm{rpm}$, respectively (Figure 9b). When the injector supply voltage was raised to DC $70 \mathrm{~V}$, the fuel injection quantities increased to $15.327 \mathrm{~g}$ from $9.314 \mathrm{~g}$ at an engine speed of $1200 \mathrm{rpm}$. As the fuel injection quantities decreased to $9.314 \mathrm{~g}$, as a result of the addition of PWM control to the 2.5 A holding currents during the last pulse duration, variations of the fuel injection quantities among engine speeds became less. Simultaneously, they became more stable due to the PWM control operation added to the 2.5 A holding currents during the last pulse durations. Thus, the following characteristic equations for the fuel injection curves can be obtained:

$$
\begin{gathered}
\mathrm{m}_{\text {fuel }}=-3 \mathrm{E}-05 V_{s}^{3}-0.0003 V_{s}^{2}+0.5339 \mathrm{~V}_{\mathrm{s}}-9.4735 \text { from } 1200 \mathrm{rpm} \text { to } 6000 \mathrm{rpm}\left(\mathrm{R}_{2}=0.9991\right) \\
\mathrm{m}_{\text {fuel }}=-0.0001 V_{s}^{3}+0.0179 V_{s}^{2}-0.5583 \mathrm{~V}_{\mathrm{s}}+12.136 \text { for exceeding } 6000 \mathrm{rpm}\left(\mathrm{R}_{2}=0.9991\right)
\end{gathered}
$$

where $\mathrm{m}_{\text {fuel }}$ is theuel injection mass $\left(\mathrm{mg} /\right.$ pulse) and $\mathrm{V}_{\mathrm{s}}$ is the power supply voltage $(\mathrm{V})$.

The holding currents controlled by PWM operation increased to 3 A during the last pulse durations. The fuel injection quantities were kept constant at $12.4 \mathrm{~g}$ between DC $40 \mathrm{~V}$ and 
$50 \mathrm{~V}$ in Figure 9c. As is shown in the results, the addition of the last pulse PWM control to the HP injector drive circuits improved the injector's performance and provided a more stable and accurate fuel injection quantities of the HP injector in the fuel supply and injection system at an operating voltage range between DC 60 and $70 \mathrm{~V}$. Therefore, it is necessary to keep the power supply voltage operating in excess of DC $60 \mathrm{~V}$, as well as adding PWM control to the 3 A holding current during the last pulse durations.

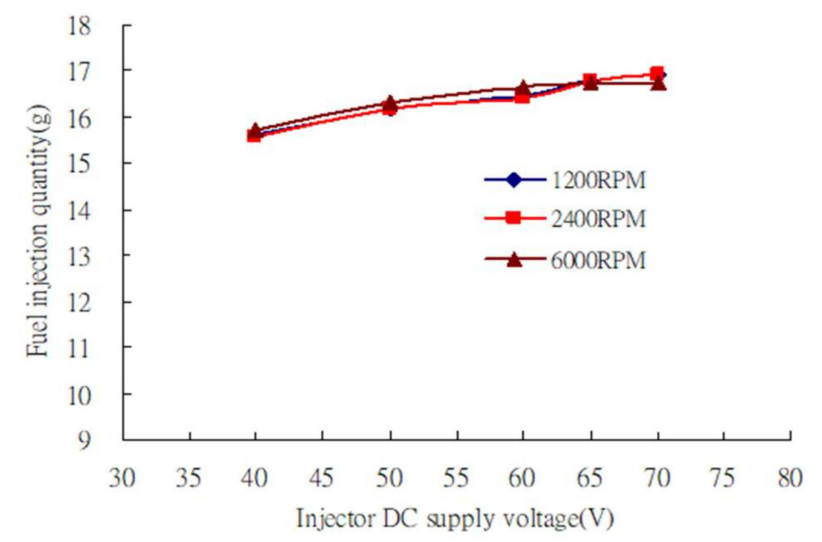

(a) Effect of the injector supply voltages on the fuel injection quantities of the HP injector (PWM control withdrawn from the last pulse duration).

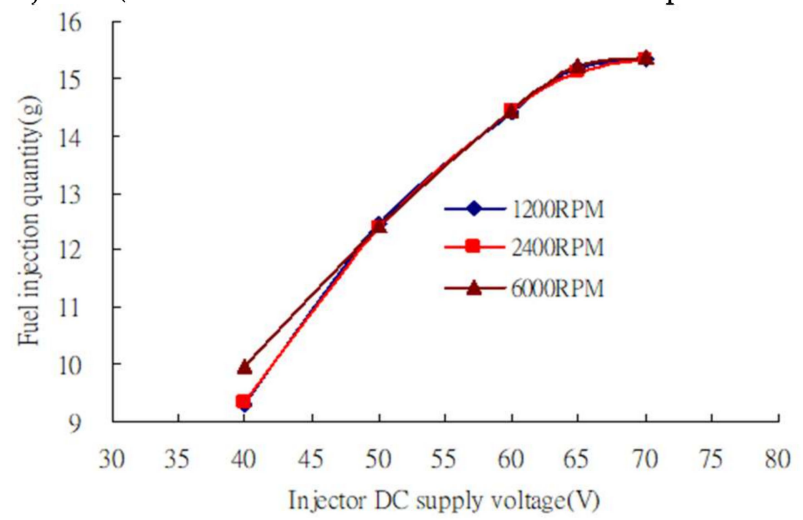

(b) Effect of the injector supply voltages on the fuel injection quantities of the HP injector (PWM control added to the last pulse duration).

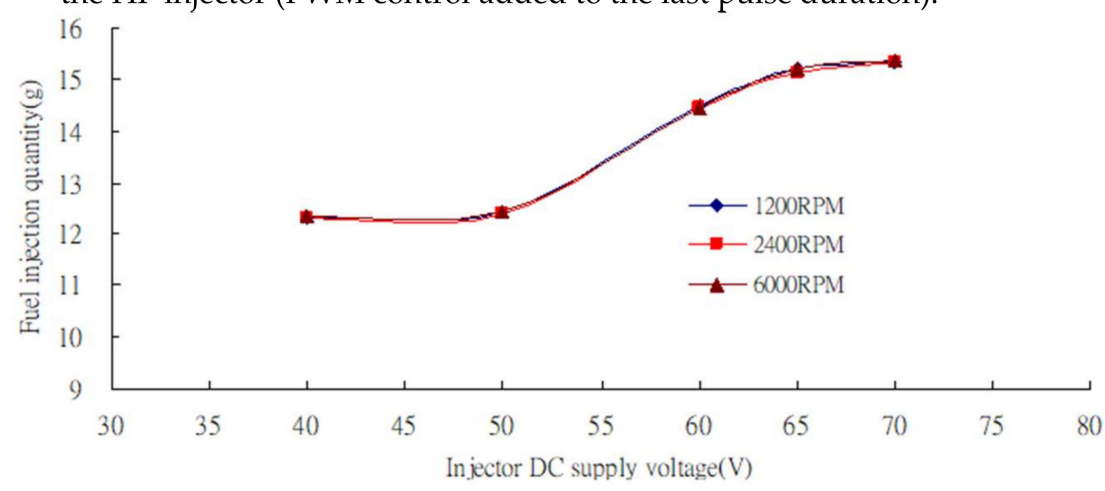

(c) Effect of the injector supply voltages on the fuel injection quantities of the GDI injector fed by the three-stage (12/5/3A) driving current (PWM control added to the last pulse duration).

Figure 9. Effect of the injector supply voltages on the fuel injection quantities of the HP injector. 


\subsection{Effect of Fuel Pressure and PWM Operation}

A high-pressure electronic fuel pump was used to supply the fuel and the fuel pressure to the HP injectors. The fuel pump needed to be large enough to supply more fuel than the maximum amount that the engine required, to ensure that the fuel pressure remains adequate at full throttle and at maximum RPM. When the engine operates at high speed or heavy load, the fuel pressure supplied by the fuel pump of motorcycle GDI engines usually dipped, while the pressure significantly influences the opening time and the fuel injection quantities of the HP injector. It was essential to investigate the fuel injection quantities of the HP injector at the various fuel supply pressures. The fuel injection quantities between two current operating modes and various fuel pressures at an engine speed of $6000 \mathrm{rpm}$ is compared in Figure 10a,b. During the testing of fuel injection quantities of the HP injector, the electrical drive circuit was designed to supply a three-stage $(12 / 5 / 3 \mathrm{~A})$ current waveform to the injector coils in order to generate the electromagnetic force to draw back and hold the nozzle needle of the GDI injector. At the various fuel pressures ranging from 60 to 100 bars, the fuel injection quantities with and without PWM control added to the last holding pulse are obtained in Figure 10a,b. From the results in Figure 10, the PWM control provided the injector with a faster closure and a higher response performance. The equations for characterizing the fuel injection curves without PWM control added to the injector drive circuit can be written as:

$$
\begin{aligned}
\mathrm{m}_{\text {fuel }} & =1.114 \mathrm{t}_{\mathrm{p}}+11.826 \text { for } 100 \text { bars } \\
\mathrm{m}_{\text {fuel }} & =1.038 \mathrm{t}_{\mathrm{p}}+11.429 \text { for } 90 \text { bars } \\
\mathrm{m}_{\text {fuel }} & =0.994 \mathrm{t}_{\mathrm{p}}+10.879 \text { for } 80 \text { bars } \\
\mathrm{m}_{\text {fuel }} & =0.932 \mathrm{t}_{\mathrm{p}}+10.195 \text { for } 70 \text { bars } \\
\mathrm{m}_{\text {fuel }} & =0.852 \mathrm{t}_{\mathrm{p}}+9.5241 \text { for } 60 \text { bars }(\mathrm{R} 2=0.9988)
\end{aligned}
$$

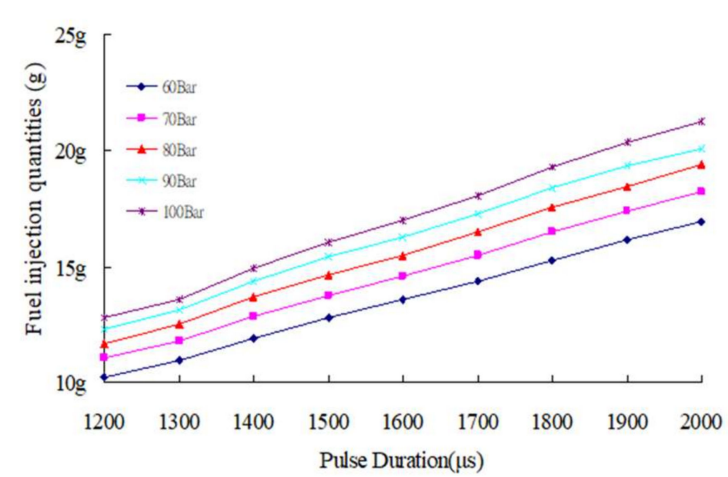

(a) PWM control added to the last pulse duration.

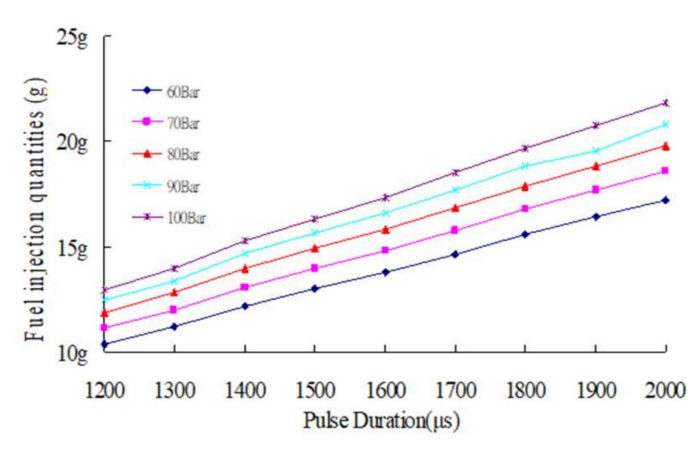

(b) PWM control withdrawn from the last pulse duration.

Figure 10. Comparison of the fuel injection quantities (a) with and (b) without PWM control at various fuel pressures at an engine speed of $6000 \mathrm{rpm}$.

The equations for characterizing the fuel injection curves for PWM control adding to the injector drive circuit, are obtained as follows:

$$
\begin{aligned}
\mathrm{m}_{\text {fuel }} & =1.0827 \mathrm{t}_{\mathrm{p}}+11.621 \text { for } 100 \text { bars } \\
\mathrm{m}_{\text {fuel }} & =0.9965 \mathrm{t}_{\mathrm{p}}+11.297 \text { for } 90 \text { bars } \\
\mathrm{m}_{\text {fuel }} & =0.9726 \mathrm{t}_{\mathrm{p}}+10.681 \text { for } 80 \text { bars } \\
\mathrm{m}_{\text {fuel }} & =0.9067 \mathrm{t}_{\mathrm{p}}+10.089 \text { for } 70 \text { bars } \\
\mathrm{m}_{\text {fuel }} & =0.8438 \mathrm{t}_{\mathrm{p}}+9.3587 \text { for } 60 \text { bars }(\mathrm{R} 2=0.9985)
\end{aligned}
$$

where $\mathrm{m}_{\text {fuel }}$ is the fuel injection mass $(\mathrm{g})$ and $\mathrm{t}_{\mathrm{p}}$ is the pulse duration $(\mu)$. 


\subsection{Effect of First-Stage Turn-on Pulse Width}

In order to understand the effects of the first-stage turn-on pulse width on the fuel injection quantities, the total drive pulse duration was adjusted between intervals of 1200-2000 $\mu$ s, the injector voltage was supplied by DC $60 \mathrm{~V}$, and the pressure of the fuel supply system was set at 100 bars. The first-stage turn-on drive pulses were set at $180 \mu$ s and $200 \mu \mathrm{s}$ to generate the $10 \mathrm{~A}$ and $12 \mathrm{~A}$ driving currents, respectively. The peak charging current amplitude during the first-stage turn-on pulse duration was interrelated to the fuel injection quantities. As for the case of $200 \mu$ s first drive pulse width in Figure 8, the drive pulse width was adequate to boost the first-stage HP injector peak current to $12 \mathrm{~A}$. The HP injector peak current was able to fully draw back the needle of the HP injector; thus, it yielded stable fuel injection quantities. The effects of the first-stage turn-on $10 \mathrm{~A}$ and $12 \mathrm{~A}$ driving currents on the fuel injection quantities of the HP injector were investigated and are discussed in Table 3. It can be seen in the table that the variations in the fuel injection quantities changed from negative to positive between the $10 \mathrm{~A}$ and $12 \mathrm{~A}$ first-stage turn-on driving currents at engine speeds of $9000 \mathrm{rpm}$. At this engine speed, the $10 \mathrm{~A}$ first-stage turn-on driving current caused a reduction in the injector supply voltage drop, and hence, resulted in more fuel quantity squirted. At the pulse intervals ranging from $1200-2000 \mu \mathrm{s}$, the fuel injection quantities increased to $20.998 \mathrm{~g}$ from $12.452 \mathrm{~g}$ and to $21.325 \mathrm{~g}$ from $12.733 \mathrm{~g}$ with $10 \mathrm{~A}$ and $12 \mathrm{~A}$ driving currents, respectively. The $12 \mathrm{~A}$ fuel injection quantities were slightly more than those of the $10 \mathrm{~A}$ first-stage turn-on driving current, as shown in Figure 11. The fuel injection quantities can be derived by the following equation for characterizing the fuel injection curves:

$$
\begin{aligned}
\mathrm{m}_{\text {fuel_12 A }} & =1.0868 \mathrm{t}_{\mathrm{p}}-11.56 \text { for all engine speeds }(\mathrm{R} 2=0.9991) \\
\mathrm{m}_{\text {fuel_10 A }} & =1.0868 \mathrm{t}_{\mathrm{p}}-11.24 \text { for all engine speeds }\left(\mathrm{R}_{2}=0.9989\right)
\end{aligned}
$$

where $\mathrm{m}_{\text {fuel }}$ is the fuel injection mass $(\mathrm{g}) ; \mathrm{t}_{\mathrm{p}}$ is the pulse duration $(\mu \mathrm{s})$.

\begin{tabular}{|c|c|c|c|c|}
\hline Pulse Width & rpm & $10 \mathrm{~A}$ & $12 \mathrm{~A}$ & Variation \\
\hline \multirow{4}{*}{$1200 \mu \mathrm{s}$} & 1200 & 12.452 & 12.733 & -0.281 \\
\hline & 2400 & 12.515 & 12.768 & -0.253 \\
\hline & 6000 & 12.529 & 12.739 & -0.210 \\
\hline & 9000 & 12.596 & 12.513 & 0.083 \\
\hline \multirow{4}{*}{$1300 \mu \mathrm{s}$} & 1200 & 13.288 & 13.566 & -0.278 \\
\hline & 2400 & 13.411 & 13.607 & -0.196 \\
\hline & 6000 & 13.384 & 13.602 & -0.218 \\
\hline & 9000 & 13.427 & 13.343 & 0.084 \\
\hline \multirow{4}{*}{$1400 \mu \mathrm{s}$} & 1200 & 14.402 & 14.866 & -0.464 \\
\hline & 2400 & 14.489 & 14.883 & -0.394 \\
\hline & 6000 & 14.549 & 14.925 & -0.376 \\
\hline & 9000 & 14.591 & 14.613 & 0.122 \\
\hline \multirow{4}{*}{$1500 \mu \mathrm{s}$} & 1200 & 15.716 & 16.001 & -0.285 \\
\hline & 2400 & 15.838 & 16.042 & -0.204 \\
\hline & 6000 & 15.893 & 16.098 & -0.205 \\
\hline & 9000 & 15.914 & 15.758 & 0.156 \\
\hline
\end{tabular}

Table 3. Comparisons between 10 and 12 A peak driving currents on fuel injection quantities. 
Table 3. Cont.

\begin{tabular}{|c|c|c|c|c|}
\hline Pulse Width & rpm & $10 \mathrm{~A}$ & $12 \mathrm{~A}$ & Variation \\
\hline \multirow{4}{*}{$1600 \mu \mathrm{s}$} & 1200 & 16.639 & 16.931 & -0.292 \\
\hline & 2400 & 16.753 & 17.298 & -0.545 \\
\hline & 6000 & 16.818 & 17.036 & -0.218 \\
\hline & 9000 & 16.844 & 16.691 & 0.153 \\
\hline \multirow{4}{*}{$1700 \mu \mathrm{s}$} & 1200 & 17.671 & 18.023 & -0.352 \\
\hline & 2400 & 17.802 & 18.237 & -0.435 \\
\hline & 6000 & 17.888 & 18.188 & -0.300 \\
\hline & 9000 & 17.924 & 17.773 & 0.151 \\
\hline \multirow{4}{*}{$1800 \mu \mathrm{s}$} & 1200 & 18.939 & 19.254 & -0.315 \\
\hline & 2400 & 19.06 & 19.308 & -0.248 \\
\hline & 6000 & 19.172 & 19.426 & -0.254 \\
\hline & 9000 & 19.198 & 18.972 & 0.226 \\
\hline \multirow{4}{*}{$1900 \mu \mathrm{s}$} & 1200 & 19.952 & 20.246 & -0.294 \\
\hline & 2400 & 20.102 & 20.444 & -0.342 \\
\hline & 6000 & 20.219 & 20.428 & -0.209 \\
\hline & 9000 & 20.238 & 19.956 & 0.282 \\
\hline \multirow{4}{*}{$2000 \mu \mathrm{s}$} & 1200 & 20.998 & 21.325 & -0.327 \\
\hline & 2400 & 21.156 & 21.342 & -0.186 \\
\hline & 6000 & 21.279 & 21.509 & -0.230 \\
\hline & 9000 & 21.308 & 20.991 & 0.317 \\
\hline
\end{tabular}

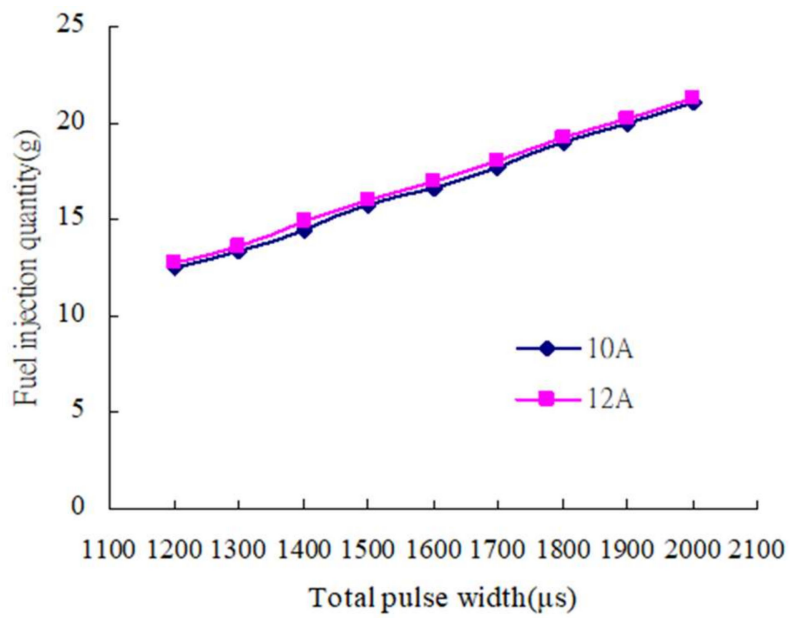

Figure 11. Comparisons between 10 and $12 \mathrm{~A}$ peak driving currents on fuel injection quantities at $6000 \mathrm{rpm}$.

Therefore, the more favorable first-stage turn-on driving currents are ranged between 12 and $10 \mathrm{~A}$ for the HP injector characteristics.

\subsection{Experiments on a 500 c.c. GDI Motorcycle Engine}

It was essential to select a high-pressure injector that was appropriate for the performance of the tested engine combustion system. Additionally, an experimental investigation on the characterization 
of the dynamic performance for the selected high-pressure injector was implemented by the design of the three-stage power MOSFETs driving circuit, injector experimental procedures, and the derived fuel injection curves using the polynomial curve fitting method. The designed injection system can be applied in other engines. In the experiments, the fuel was directly injected into the combustion chamber of the 500 c.c. motorcycle GDI engine during the intake stroke, producing a homogeneous mixture to achieve good air-fuel ratio control for GDI engine operations. Superior fuel injection timing was observed at the range between $40^{\circ}$ and $70^{\circ}$ ATDC in intake stroke, with the engine operating speeds from idle speed to $6000 \mathrm{rpm}$. The air-fuel ratio (AFR) is controlled and was close to 14.7 (stoichiometric) in the homogeneous combustion operation.

The control signal and driving current waveforms of the 500 c.c. GDI engine operating at $4500 \mathrm{rpm}$ and $6000 \mathrm{rpm}$ are illustrated in Figure 12a,b, respectively. In the figures, green and blue waveforms describe the proximity switch signal on the engine camshaft and the $\mathrm{Z}$ signal of the engine encoder. The orange waveform represents the signal of the TDC on intake. The GDI injector driving current is plotted in the pink waveform. The GDI engine has the advantage of faster power response and an increase of its engine torque with the throttle opening position. As seen in Figure 13, the 500 c.c. motorcycle GDI engine produces less torques at speed lower than $4000 \mathrm{rpm}$, due to slow turbulence and poor vaporization of fuel film on the piston crown.

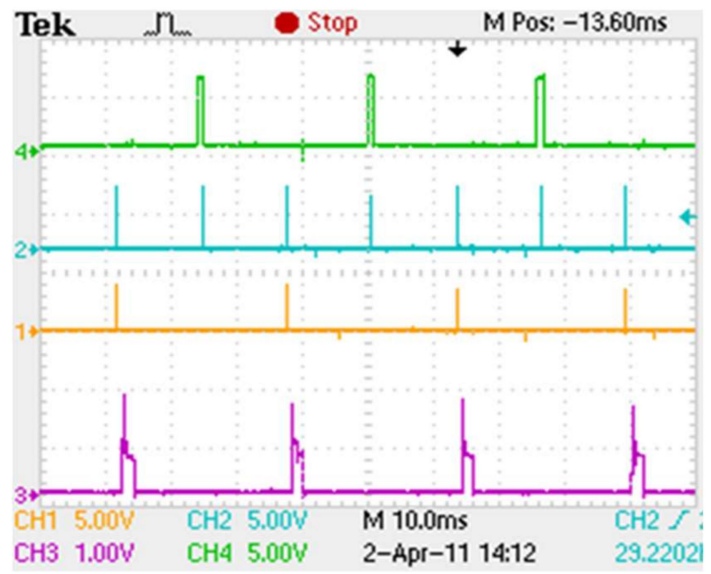

(a) Control signal and driving current waveforms of the 500 c.c GDI engine operating at $4500 \mathrm{rpm}$.

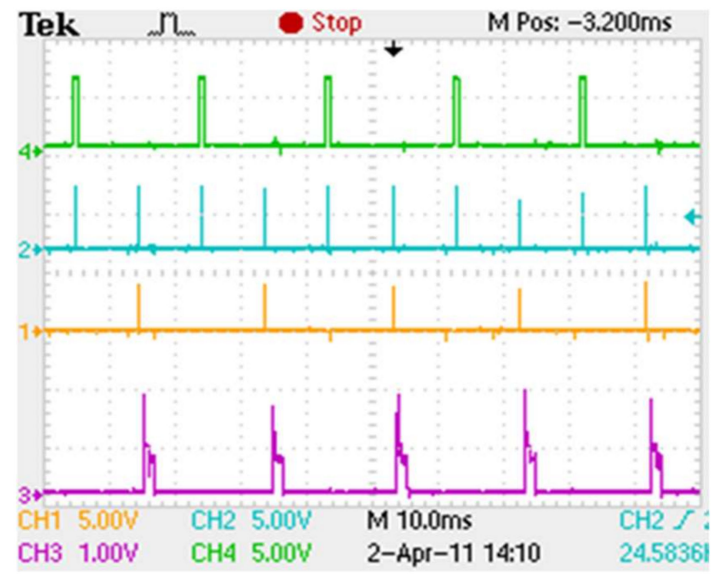

(b) Control signal and driving current waveforms of the 500 c.c GDI engine operating at $6000 \mathrm{rpm}$.

Figure 12. Control signal and driving current waveforms of the 500 c.c GDI engine.

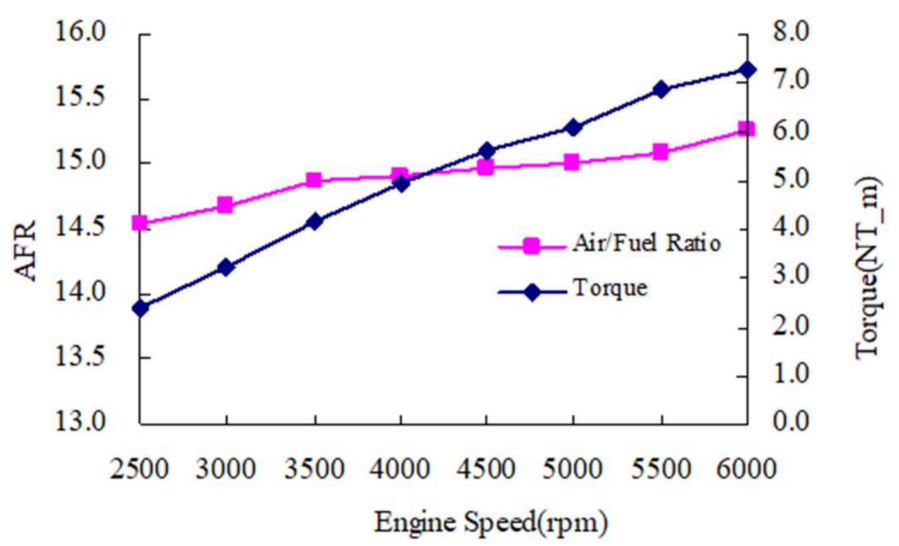

Figure 13. Torque and Air/fuel ratio of the 500 c.c. motorcycle GDI engine at various speeds.

The specific geometry and shaped cavity of the piston crown can be utilized to obtain the swirl-dominated and tumble-dominated flow to achieve the superior stratified combustion in the GDI engine during the low-speed operation. The combined effects lead to an intensified swirl and 
augmented turbulence intensity to enhance the fuel-air mixing. Thus, the engine torque is improved at low speed engine operations. Air path control in the engine is the key for AFR control. The air-fuel ratio was significantly affected by the air flow and fuel injection time. In the real engine, the air-fuel ratio (AFR) transient condition of the 500 c.c. motorcycle engine would lead to a $\pm 10 \%$ offset near the stoichiometry condition, using the derived fuel injection curves described in this paper. The injected fuel quantities of the GDI engine varied with different engine speeds to achieve an air-fuel ratio ranging between 14.5 and 15.2, as shown in Figure 13. The figure illustrates the engine's air-fuel ratio control during a transition from stoichiometric to homogenous combustion. The HP fuel GDI injector provided more stable and accurate fuel injection quantities at an operating speed range between $1500 \mathrm{rpm}$ and $6000 \mathrm{rpm}$. In a 500 c.c. motorcycle GDI engine test, the fuel injection quantities of the GDI injector in the engine are controlled by using the derived fuel injection curves. The engine speed was limited to $6000 \mathrm{rpm}$, because of the mechanical resonance occurring at the engine test stand between $6200 \mathrm{rpm}$ and $6300 \mathrm{rpm}$. It is dangerous to achieve the complete HP fuel injecting experiment for the 500 c.c. motorcycle GDI engine if it exceeds $6000 \mathrm{rpm}$.

\section{Conclusions}

As can be seen from the results, an injector drive circuit was developed to improve the fuel injection of an HP fuel injector, reducing the lifetime of solenoid coils of an injector actuator during the fuel injection operation. PWM control was added to the power MOSFET drive circuit to quickly turn off the injection of HP fuel injectors. The injector drive circuit has been successfully achieved in many high-performance and long-lasting GDI fuel injection experiments to verify its performance and feasibility, meeting the operating characteristics of GDI injectors. Experimental studies were conducted to characterize the fuel injection curve of the HP fuel injector. Based on the operating requirements of the GDI fuel injector, an adjustable injector drive circuit was developed using a reference current profile. The GDI injector was calibrated by the injector drive circuit to improve the stability of automotive engines during their operation. Experimental investigations were used to characterize the performance of the injector drive circuit. An experimental investigation on the characterization of the dynamic performance for the selected high-pressure injector was implemented in the paper by the design of an injector drive circuit, injector experimental procedures, and the derived fuel injection curves using polynomial curve fitting method. Some main conclusions can be drawn:

1. The designed GDI injector drive circuit improved the injector's performance and provided more stable and accurate fuel injection quantities in the HP fuel injecting system. The power supply voltage of the HP injector needed to be operated and held in excess of DC $60 \mathrm{~V}$, to squirt adequate fuel quantities. Otherwise, the 500 c.c. motorcycle GDI engine would run a transition from homogeneous combustion to lean burn combustion, or even misfire.

2. The developed injector drive circuit was realized well in both experiments and practical applications. The experimental results show that the fuel injection quantities without the PWM control mode are more than those with the PWM control mode for the injecting tests of the HP GDI injector. The fuel injection quantities increased significantly, due to the PWM control withdrawn from the third-stage holding current $(2.5 \mathrm{~A})$. This holding current was adequate to pick up and hold the HP nozzle needle, and hence, the HP injector can sustain the injection of fuel during the last pulse operation. Therefore, the HP GDI injector should be supplied by a three-stage 12/5/2.5 A without PWM control modes added to the last pulse duration. Third-stage holding current amplitudes should be kept higher than $3 \mathrm{~A}$ if PWM control modes are added to the last pulse duration to achieve the HP GDI injector close faster and achieve the lowest amount of power consumption.

3. The HP fuel GDI injector provides a more stable and accurate fuel injection quantities at an operating speed range between $1500 \mathrm{rpm}$ and $6000 \mathrm{rpm}$. In a 500 c.c. motorcycle GDI engine test, the fuel injection quantities of the GDI injector in the engine were controlled by using the derived fuel injection curves. The engine speed was limited to $6000 \mathrm{rpm}$, because of the mechanical 
resonance occurring at the engine test stand between $6200 \mathrm{rpm}$ and $6300 \mathrm{rpm}$. It is dangerous to achieve the complete HP fuel injecting experiment when the 500 c.c. motorcycle GDI engine exceeds $6000 \mathrm{rpm}$.

Author Contributions: Wen-Chang Tsai proposed to design a new electrical drive circuit for the HP GDI injector. The designed electric drive circuit was tested to verify its feasibility and performed. Wen-Chang Tsai carried out the drive circuit, which allows the HP fuel supply system its ability to operate stably and assures accurate fuel injection quantities to precisely control the expected AFR in the 500 c.c. motorcycle GDI engine operation. Wen-Chang Tsai and Tung-Sheng Zhan collaboratively do newly experimental results for the tested engine system to satisfy and address the reviewer's comments. The authors discussed the experimental results and revised the manuscript.

Funding: This research is supported by Ministry of Science and Technology under Project No. MOT-106-2221-E-244-007.

Acknowledgments: The author would like to thank his colleagues, Peng-Cheng Yu (AERC, Taiwan) who helped us set up the experimental engine system.

Conflicts of Interest: The author declares no conflict of interest.

\section{Nomenclature}

\begin{tabular}{|c|c|c|}
\hline Symbols & Description & Unit \\
\hline SGDI & Spray Guided Direct Injection & \\
\hline $\mathrm{HP}$ & High-pressure & bar \\
\hline GDI & Gasoline-direct-injection & \\
\hline AFR & Air-fuel ratio & \\
\hline TTL & Transistor-Transistor Logic & \\
\hline ICs & Integrated Circuits & \\
\hline MOSFET & Metal oxide semiconductor field effect transistor & \\
\hline PWM & Pulse width modulation & \\
\hline ECU & Electronic control unit & \\
\hline PFI & Port fuel injection & \\
\hline PCB & Printed circuit board & \\
\hline KVL & Kirchhoff's Voltage Law & \\
\hline TDC & Top dead left & \\
\hline rpm & revolutions per minute & \\
\hline Ip1 & First turn-on pulse signal & \\
\hline mfuel & Fuel injection mass & $\mathrm{g}$ \\
\hline tp & Injection pulse duration & $\mu \mathrm{s}$ \\
\hline
\end{tabular}

\section{References}

1. Zhao, F.; Lai, M.C.; Harrington, D.L. Automotive spark-ignited direct-injection gasoline engines. Prog. Energy Combust. Sci. 1999, 25, 437-562. [CrossRef]

2. Wang, C.; Xu, H.; Herreros, J.M.; Wang, J.; Cracknell, R. Impact of fuel and injection system on particle emissions from a GDI engine. Appl. Energy 2014, 132, 178-191. [CrossRef]

3. Xu, H.; Ma, X.; Sarangi, A.K.; Weall, A.; Krueger-Venus, J. Fuel injector deposits in direct injection spark-ignition engines. Prog. Energy Combust. Sci. 2015, 50, 63-80. [CrossRef]

4. Leach, F.; Knorsch, T.; Laidig, C.; Wiese, W. A Review of the Requirements for Injection Systems and the Effects of Fuel Quality on Particulate Emissions from GDI Engines; SAE Technical Paper; SAE International: Warrendale, PA, USA, 2018.

5. Raza, M.; Chen, L.; Leach, F.; Ding, S. A review of particulate number (PN) emissions from gasoline direct injection (GDI) engines and their control techniques. Energies 2018, 11, 1417. [CrossRef]

6. Guo, H.; Gao, W.; Liu, X.; Zhang, Z. Study on measurement system of the dynamic performances for an electronic fuel injector. In Proceedings of the 2010 International Conference on Measuring Technology and Mechatronics Automation (ICMTMA 2010), Changsha, China, 13-14 March 2010; pp. 608-611. 
7. Zhang, X.; Palazzolo, A.; Kweon, C.B.; Thomas, E.; Tucker, R.; Kascak, A. Direct fuel injector power drive system optimization. SAE Int. J. Engines 2014, 7, 1137-1154. [CrossRef]

8. Zhang, J.Q.; Ouyang, G.Y. Optimization design of the electronically controlled injector. In Proceedings of the IEEE International Conference on Mechatronics and Automation, Changchun, China, 9-12 August 2009; pp. 1996-2001.

9. Tsai, W.C.; Wu, Z.H. Use of Taguchi method to optimize the operating parameters of a high-pressure injector driving circuit. Appl. Mech. Mater. 2011, 130, 2795-2799. [CrossRef]

10. Tsai, W.C.; Yu, P.C. Design of the electrical drive for the high-pressure GDI injector in a 500cc motorbike engine. Int. J. Eng. Ind. 2011, 2, 70-83.

11. Cheng, Q.; Zhang, Z.; Xie, N. Power losses and dynamic response analysis of ultra-high speed solenoid injector within different driven strategies. Appl. Therm. Eng. 2015, 91, 611-621. [CrossRef]

12. Bai, Y.; Fan, L.Y.; Ma, X.Z.; Peng, H.L.; Song, E.Z. Effect of injector parameters on the injection quantity of common rail injection system for diesel engines. Int. J. Automot. Technol. 2016, 17, 567-579. [CrossRef]

13. Chen, C.; Li, Y.Q.; Wang, D.F. The Design of Driving Circuit of GDI Injector and Experimental Verification based on L9707 Chip. Intern. Combust. Engine Powerpl. 2010, 1, 1-6.

14. Hu, Y.Z.; Teng, Q.; Liu, J.S. Development of a driver circuit for GDI high pressure injector. Electron. Des. Eng. 2011, 19, 141-144.

15. LM1949 Injector Drive Controller Datasheet; Texas Instruments: Dallas, TX, USA. 2013. Available online: http:/ / www.ti.com/lit/ds/symlink/lm1949.pdf (accessed on 28 September 2018).

16. Bosch EV1 high-pressure fuel injector; Professional Fuel Injector Cleaning and Flow Testing Service Glenville NY, USA. 2018. Available online: http:/ / injectorrepair.com/knowledge-base/ (accessed on 28 September 2018).

(C) 2018 by the authors. Licensee MDPI, Basel, Switzerland. This article is an open access article distributed under the terms and conditions of the Creative Commons Attribution (CC BY) license (http:/ / creativecommons.org/licenses/by/4.0/). 